\title{
Preparation and in vitro characterization of monoclonal antibody ranibizumab conjugated magnetic nanoparticles for ocular drug delivery
}

\author{
Neşe Ayata1, Ali Demir Sezer ${ }^{(1 *}$, Seyda Bucak², Eda Tahir Turanlı ${ }^{3}$ \\ ${ }^{1}$ Department of Pharmaceutical Biotechnology, Faculty of Pharmacy, Marmara University, \\ Haydarpaşa, Istanbul, Turkey, ${ }^{2}$ Department of Chemical Engineering, Faculty of Engineering, \\ Yeditepe University, Ataşehir, Istanbul, Turkey, ${ }^{3}$ Department of Molecular Biology and Genetics, \\ Faculty of Science and Letters, İstanbul Technical University, Sarlyer, Istanbul, Turkey
}

\begin{abstract}
Gold coated magnetite nanoparticles were prepared and coated with ranibizumab as an ocular drug delivery system. The surface morphologies of the nanoparticles were determined by Scanning Electron Microscopy (SEM). The size and surface charge were determined by using the dynamic light scattering (DLS) technique. Crystallographic properties of the gold coated $\mathrm{Fe}_{3} \mathrm{O}_{4}$ nanoparticles were recorded on X-ray diffractometer (XRD) the XRD pattern of nanoparticlees were shown to have uniqe $\mathrm{Fe}_{3} \mathrm{O}_{4}$ and gold peaks. Conjugation of ranibizumab onto nanoparticles was achieved using the physical adsorption method. The amount of ranibizumab on the surface of the nanoparticles was determined by thermogravimetric analysis (TGA). In the in vitro release studies performed using UV spectroscopy; it was found that almost $60 \%$ of antibodies were released within the first 30 minutes. Antibody activity after release studies was also proved with ELISA. Non-toxicity of gold coated $\mathrm{Fe}_{3} \mathrm{O}_{4}$ particles were proved with MTT. Results of the studies, showed that the antibody conjugated magnetic nanoparticle system could be a potential treatment system for ocular diseases.
\end{abstract}

Keywords: Ranibizumab. Monoclonal antibody. Drug delivery. Magnetic nanoparticles. Cell culture.

\section{INTRODUCTION}

Age-related Macular Degeneration (AMD) is the major cause of irreversible vission loss in the world in people 50 years of age or elderly population in the world (Eter et al., 2006). AMD can be present in two forms, atrophic (also known as non-neovascular AMD, geographic atrophy or dry AMD) or choroidal neovascular AMD (CNV) (also called exudative or wet AMD) (Van Leeuwen et al., 2003). In the 1980s laser photocoagulation was used for the treatment of neovascular AMD. Treatment with laser was effective in reducing long-term severe visual loss, however it was limited by lack of vision gain and high recurrence rates (50\%) (Lim et al., 2012).

*Correspondence: A.D. Sezer, Department of Pharmaceutical Biotechnology. Marmara University, Haydarpaşa 34668, Istanbul, Turkey. Tel: +90 21641429 63. Fax: +90 21634529 52. E-mail: adsezer@marmara.edu.tr
Photodynamic therapy (PDT) with verteporfin has been used in the 1990s for AMD treatment. In the treatment of AMD, verteporfin is used as the photosensitizer and is administered intravenously. After accumulation of verteporfin in neovascular membranes, the dye is activated with infrared light. This process generates oxygen-free radicals that damage the endothelium, promoting closure of newly formed vessels (Lim et al., 2012; Schmidt-Erfurth, Hasan, 2000). Intravitreal antiangiogenic therapies are currently the primary therapy for neovascular age-related macular degeneration. Intravitreal injections limit therapy to the eye, avoiding systemic administration and possibly reducing the incidence of systemic adverse effects (Jager et al., 2008).

New vessel growth is a complex process requiring activation of several receptors and growth factors. Of these growth factors, the vascular endothelial growth factor (VEGF) is essential for proper physiological 
angiogenesis. Therefore, the target of the treatments is the inhibition of VEGF (Penn et al., 2008). Sodium Pegaptanib (Macugen, Eyetech Pharmaceuticals, Inc., New York, NY) was approved by the US Food and Drug Administration (FDA) in December 2004 for the treatment of neovascular AMD (Eter et al., 2006, Kourlas and Schiller, 2006). VEGF Trap (Aflibercept, Regeneron, Tarrytown, New York, USA) is a fusion protein that bind to VEGF, has recently received FDA approval for the treatment of neovascular age-related macular degeneration treatment (Lim et al., 2012). Over the past two decades, the most common treatment used for neovascular AMD is based on monoclonal antibody dependent inhibition of VEGF. By so doing regression of revascularization and improved vision is provided (Volz, Pauly, 2015). Bevacizumab (Avastin, Genentech, Inc., South San Francisco, CA) is a humanized monoclonal antibody that binds to VEGF, which was designed for IV administration and is approved for the treatment of colorectal cancer (Avery et al., 2006). It is also increasingly being used off-label as intravitreal therapy for neovascular age-related macular degeneration since 2005 (Jager et al., 2008).

Ranibizumab (Lucentis ${ }^{\circledR}$, Genentech, Inc., San Francisco, CA, USA) is a humanized antigen-binding fragment (Fab) that neutralizes all VEGF-A isoforms. Ranibizumab was derived from the murine monoclonal antibody A4.6.1., such as bevacizumab (Spitzer et al., 2008). However, bevacizumab was derived from FabFab-12 while ranibizumab was derived from a different humanized anti-VEGF Fab variant known as MB1.6. through a series of phage display steps. Affinity selection using phage display technology increased the affinity of Ranibizumab for VEGF-A by several times (Spitzer et al., 2008; Chen et al., 1999; Baca et al., 1997). Because of the improved affinity improvement, ranibizumab was 5- to 20 - fold more potent than bevacizumab in spite of the fact that it had only one antigen binding site. Also the Lack of the Fc (Fragment crystallizable) region prevents the promotion of intraocular inflammation after intravitreal injection (Spitzer et al., 2008, Ferrara et al., 2006). In June 2006, ranibizumab was approved by FDA for the treatment of neovascular AMD (Ferrara et al., 2006).

Local delivery of antibodies can provide substantial benefits such as; higher local bioavailability, reduced systemic drug exposure, lower dose of antibody and consequently reduced side effects. However, there are some factors that limit local antibody applications, such as increased dose frequency due to the short life span of antibodies, invasiveness of the administration to some sites and accordingly reactions at the injection site (Schweizer et al., 2014; Orive et al., 2003). For example, intravitreal injections are used for AMD treatment. However, the treatment efficacy is limited by repeated applications, systemic exposure, and poor availability in the posterior segments of the eye. Intravitreal applications also have disadvantages such as patient discomfort, eye infections, high intraocular pressure, retinal vascular occlusion or retinal detachment (Witting et al., 2015). Drug delivery systems can provide more effective treatment by removing these limitations.

Nanoparticles are very small particles that vary in size from $10 \mathrm{~nm}$ to $1000 \mathrm{~nm}$ and which consist of macromolecular substances (Singh, Lillard, 2009). There are many types of nanoparticles with differing sizes, shapes, composition and functionality. Some of these are liposomes, albumin bound nanoparticles, polymeric nanoparticles, magnetic nanoparticles and quantum dot (Wang, Wang, 2014). Nanoparticles have been used in many areas such as engineering, electronics and computers, cosmetic, environmental, food, transportation and biomedicine. Some examples of nanoparticle applications in biomedicine include detecting analytes, pathogens, cells or molecular functions as a biosensor, novel labels and contrast agents in molecular imaging, targeted drug delivery, diagnosis of diseases, gene delivery and biocompatible coatings for implants (Wang, Wang, 2014; Nagarajan, Hatton, 2008).

Magnetic nanoparticles show a response to an applied magnetic field. Manipulation by the applied external magnetic field makes them attractive in targeting studies (Issa et al., 2013). Magnetic nanoparticles have widespread application in biotechnology, biomedical, material science, engineering and environmental areas. "Magnetite" $\left(\mathrm{Fe}_{3} \mathrm{O}_{4}\right)$ and its oxidized form "Maghemite" $\left(\gamma-\mathrm{Fe}_{2} \mathrm{O}_{3}\right)$ are the most commonly used magnetic nanoparticles because of theirtheir non-toxic and biocompatibility properties (Akbarzadeh et al., 2012). In order to control the toxicity properties of magnetic nanoparticles, the surface can be coated with different materials such as polymer, silica, carbon or gold (Bucak et al., 2012). Biomedical application can be classified into two categories, two categories: in vitro and in vivo. For in vitro applications, the main use is for diagnostics applications such as separating and selection, magnetic resonance imaging and bioseperation of biomolecules, such as protein, cell, 
DNA/RNA, microorganism. In vivo applications are therapeutic applications such as hyperthermia, drug delivery and diagnostic applications such as NMR imaging (Issa et al., 2013; Frimpong, Hilt, 2010).

Gold is an inert element and very useful as a coating material for protecting magnetic nanoparticles, its unique biocompatibility, versatility in surface modification and high catalytic properties. For these reasons gold coating of magnetic nanoparticles has attracted much attention over the past several years as they can be used in biotechnological and biomedical areas, including drug delivery (Ahmed et al., 2014; Xing et al., 2015).

Physical adsorption method uses non-covalent modes of binding based on a combination of electrostatic and hydrophobic interactions of the antibody and the gold surface. The antibodies or other functionalized groups are nonspecifically adsorbed onto gold nanoparticles while still keeping the nanoparticles negatively charged, providing stability in colloidal solution. Non-covalent technique is described as spontaneous absorption of antibodies onto the surface of citrate stabilized nanoparticles; there are several types of interactions which may occur in this process including hydrophobic interactions and ionic interactions. Hydrophobic interactions are due to attraction between hydrophobic parts of the antibody and the metal surface which results in the formation of a noncovalent bond. Positively charged groups are abundant in antibodies i.e., positively charged amino acids and the $\mathrm{N}$-terminal are present. Ionic interactions are formed between these groups and the negatively charged surface of the particles (Jazayeri et al., 2016).

The toxicity of iron oxide nanoparticles and gold nanoparticles were evaluated and it was proved that these materials are non-toxic for ocular tissues (Raju et al., 2011; Söderstjerna et al., 2014; Hun Kim et al., 2009; Soenen et al., 2011). From this point of view, it is suggested that prepared gold coated nanoparticles in this study can be an alternative drug delivery system for ocular treatment.

In the present work, a drug delivery system that can be manipulated by applying an external magnetic field is developed for use in ocular treatments. For this purpose, ranibizumab antibody conjugated gold coated magnetic nanoparticles were prepared. Furthermore, in vitro characterization studies were performed on particles, including: drug loading and release profile, Scanning Electron Microscopy (SEM), Thermogravimetric Analysis (TGA), Dynamic Light Scattering (DLS), and X-Ray Diffraction (XRD). Antibody activity after release studies was proved with ELISA. Also toxicity of gold coated $\mathrm{Fe}_{3} \mathrm{O}_{4}$ particles was evaluated with MTT test using HUVEC cell culture.

\section{MATERIAL AND METHODS}

\section{Material}

Gold (III) chloride trihydrate was purchased from Sigma-Aldrich Co. (USA). Ranibizumab was a generous gift from ATABAY Kimya San. ve Tic. A.S. (TURKEY) and all the other chemicals used were analytical grade.

\section{Methods}

\section{Preparation of $\mathrm{Fe}_{3} \mathrm{O}_{4}$ Nanoparticles}

$\mathrm{Fe}_{3} \mathrm{O}_{4}$ magnetic nanoparticles were prepared by using co-precipitation method (Gupta et al., 2005). In this method nanoparticles were synthesized through coprecipitation of $\mathrm{Fe}^{3+}$ and $\mathrm{Fe}^{2+}$ with sodium hydroxide. Initially $80 \mathrm{~mL}$ distilled water was de-aerated with nitrogen gas for $1 / 2$ hours. The solution was heated up to $80^{\circ} \mathrm{C}$ in a reactor while stirring mechanically. After $1 / 2$ hour, $0.648 \mathrm{~g}$ of iron chloride $\left(\mathrm{FeCl}_{3}\right)$ and $0.559 \mathrm{~g}$ of iron sulfate heptahydrate $\left(\mathrm{FeSO}_{4} \cdot 7 \mathrm{H}_{2} \mathrm{O}\right)$ were dissolved in the reaction medium under nitrogen gas. After 15 minutes, $20 \mathrm{~mL}$ of $1.5 \mathrm{M}$ sodium hydroxide $(\mathrm{NaOH})$ was added as a base. Upon this addition, blackening of the solution was observed immediately, which suggests the formation of magnetite nanoparticles. These chemicals were mixed for another $1 / 2$ hour and then, the mixture was cooled down to room temperature. After synthesis, magnetite nanoparticles were collected by magnetic separation and the precipitate was washed twice with distilled water. The stock $\mathrm{Fe}_{3} \mathrm{O}_{4}$ nanoparticle solution was prepared in $50 \mathrm{~mL}$ of distilled water.

\section{Preparation of Gold Coated $\mathrm{Fe}_{3} \mathrm{O}_{4}$ Nanoparticles}

Initially $35 \mathrm{mg}$ of $\mathrm{HAuCl}_{4} \cdot 3 \mathrm{H}_{2} \mathrm{O}$ was dissolved in $120 \mathrm{~mL}$ of distilled water. This solution was then heated under reflux to boiling-point under vigorous stirring in a reactor. $5 \mathrm{~mL}$ of prepared stock $\mathrm{Fe}_{3} \mathrm{O}_{4}$ nanoparticle dispersion was slowly added to $\mathrm{HAuCl}_{4}$ solution. After $10 \mathrm{~min}, 5 \mathrm{~mL}$ of $80 \mathrm{mM}$ sodium citrate solution was slowly added to the reaction mixture. This mixture was boiled under reflux with vigorous stirring for $5 \mathrm{~min}$; the heating was then turned off, and the mixture was cooled to room temperature (Majouga et al., 2015). After 
synthesis, nanoparticles were collected by magnetic separation and the precipitate was washed twice with distilled water. Red-brownish colored particles were obtained. Stock gold coated $\mathrm{Fe}_{3} \mathrm{O}_{4}$ nanoparticle solution was prepared in $50 \mathrm{~mL}$ of distilled water.

$\mathrm{Fe}_{3} \mathrm{O}_{4}$ concentration of gold coated nanoparticles was determined using "Tiron Metal Test" method (Bucak, Rende, 2013). Fe ions and tiron forms a colored complex which has a maximum absorbance value and intensity at $480 \mathrm{~nm}$ spectrophotometrically (Lambda, Perkin Elmer, U.S.). This absorbance value is measured in order to obtain the concentration of magnetite by using below equation:

$\mathrm{C}(\mathrm{g} / \mathrm{ml})=\frac{(\text { ABS at } 480 \mathrm{~nm}) \times(\text { Dilution factor }) \times 231.52 \times 25}{39986 \times 162.15 \times 0.1}$

In this test, $0.1 \mathrm{~mL}$ nanoparticle solution was mixed with $0.4 \mathrm{~mL}$ of concentrated (37\%) hydrochloric acid, this solution was then heated with a heat gun until the color of the solution changed to yellow. After color change, obtained solution was mixed with the $0.083 \mathrm{~g} / \mathrm{mL}$ of tiron solution. $4 \mathrm{M}, 3 \mathrm{~mL}$ of sodium hydroxide solution is added to the solution that turns red immediately. Finally, water was added until the final volume reaches $25 \mathrm{~mL}$. In order to measure the absorbance of the final solution, dilution was performed.

\section{Preparation of Antibody Conjugated Nanoparticles}

Antibodies were conjugated on nanoparticles using the "Physical Adsorption" method (Singh et al., 2009). In this method antibodies and nanoparticles were incubated together. 30, 45 and $60 \mu \mathrm{g}$ of antibodies were diluted in $300 \mu \mathrm{L}$ of $20 \mathrm{mM}$ HEPES buffer (pH:6.8). $250 \mu \mathrm{L}$ of stock gold coated $\mathrm{Fe}_{3} \mathrm{O}_{4}$ nanoparticle solution was taken and washed with distilled water by the help of a magnet. Then nanoparticles were diluted in $300 \mu \mathrm{L}$ of $20 \mathrm{mM}$ HEPES buffer (pH:6.8). Antibody solution was added into prepared nanoparticle solution and mixed for 2 hours with shaker at $100 \mathrm{rpm}$.

\section{In vitro Release Studies and Conjugation Efficiency}

After conjugation procedure, antibody conjugated nanoparticles were collected by the help of a magnet. Supernatant solutions were collected into different vials. In order to obtain conjugation efficiency, absorbance values of collected supernatant was measured between
200 and $700 \mathrm{~nm}$ by using UV-Vis Spectroscopy. Instead of the taken buffer, $600 \mu \mathrm{L}$ of PBS buffer ( $\mathrm{pH}: 7.4)$ was added as release medium onto collected nanoparticles. The shaking procedure was continued at $100 \mathrm{rpm}$ for 48 hours. At various time intervals, nanoparticles were held by magnet from outside of the vial and $100 \mu \mathrm{L}$ of samples were obtained. An equal volume of fresh medium was added. In order to obtain release amount, collected samples were measured between 200 and $700 \mathrm{~nm}$ by using UV-Vis Spectroscopy (SPECTROstar, BMG Labtech, Germany).

\section{Nanoparticle Physicochemical Characterization}

The morphology and surface of the gold coated $\mathrm{Fe}_{3} \mathrm{O}_{4}$ particles were examined through Scanning Electron Microscopy (SEM; JEOL, JSM-5200, Japan). Before this analysis nanoparticles were dried overnight in a freeze-dryer (Scanvac, Coolsafe, Denmark). overnight. The dried nanoparticles were used for SEM images and surface morphology was determined.

\section{Particle Size and Zeta Potential Determination}

The hydrodynamic size of gold coated $\mathrm{Fe}_{3} \mathrm{O}_{4}$ particles were measured by dynamic light scattering (DLS) using a NanoS Zeta Sizer (Malvern ZetasizerNano ZS, U.K.). The measurements were performed at $25{ }^{\circ} \mathrm{C}$ with a laser diode illuminated light scatter sensor before and after antibody conjugation. After conjugation of different concentrations of antibodies, nanoparticles were collected with a magnet and the supernatant buffer was discharged. Then antibody conjugated nanoparticles were dissolved in distilled water as dispersion medium and measurements were performed. The average particle sizes with error ranges were obtained from three measurements of each sample.

The zeta potential of gold coated $\mathrm{Fe}_{3} \mathrm{O}_{4}$ particles were measured by electrophoretic mobility at $25{ }^{\circ} \mathrm{C}$ using a NanoS Zeta Sizer (Malvern Zetasizer-Nano ZS, U.K.) which was used in the hydrodynamic size measurements. The measurements were performed before and after antibody conjugation. After conjugation of different concentration of antibodies, nanoparticles were collected with a magnet and supernatant buffer was discharged. Antibody conjugated nanoparticles were then dissolved in distilled water as dispersion medium and measurements were performed. The surface charges with error ranges were obtained from three measurements of each sample. 


\section{$X$-ray Diffraction $(X R D)$}

The crystallographic properties of the gold coated $\mathrm{Fe}_{3} \mathrm{O}_{4}$ nanoparticles were recorded on an X-ray diffractometer (XRD; Bruker - D8 Advance, U.S.). Before the test, the samples were dried overnight in a freeze-dryer (Scanvac, Coolsafe, Denmark).

\section{Thermogravimetric Analysis (TGA)}

Thermogravimetric analysis (TGA; PerkinElmer Pyris 1 TGA, U.S.) was used to indicate conjugation of antibodies onto gold coated $\mathrm{Fe}_{3} \mathrm{O}_{4}$ nanoparticle surface and to determine the amount of conjugated antibody. Before the test, the samples were dried overnight in a freeze-dryer (Scanvac, Coolsafe, Denmark). TGA of the gold coated $\mathrm{Fe}_{3} \mathrm{O}_{4}$ nanoparticles with and without antibodies were performed at a heating speed of $10{ }^{\circ} \mathrm{C} /$ min under nitrogen where the temperature changed from $25^{\circ} \mathrm{C}$ to $600{ }^{\circ} \mathrm{C}$. The difference in weight loss was then determined.

\section{Enzyme Linked Immunosorbent Assay (ELISA) Test}

After in vitro drug release studies, sample concentrations were quantified using a commercially available ranibizumab ELISA kit (Alpha Diagnostic International, USA) in accordance with manufacturer's instructions. OD readings were performed at $450 \mathrm{~nm}$ and antibody amounts in samples were calculated according to the standards used.

\section{Cell Culture Experiments}

Human umbilical vein endothelial cells (HUVECs, ATCC-CRL-1730) were cultured in M199 medium (PAN Biotech, Germany) supplemented with $20 \%$ FBS (PAN Biotech, Germany), 2\% glutamine, $1 \%$ penicillin/streptomycin (PAN Biotech, Germany) and maintained at $37{ }^{\circ} \mathrm{C}$ in a humidified $5 \% \mathrm{CO}_{2}$. Cultures were maintained with T75 flask and 96 well plates were used for MTT tests. Nanoparticles used for cell culture studies were sterilized with UV for 30 minutes before experiments. Antibody and nanoparticle dilutions were performed in M199 medium containing $2 \%$ FBS.

The cytotoxicity of gold coated $\mathrm{Fe}_{3} \mathrm{O}_{4}$ nanoparticles was determined using a commercially available MTT kit (Cayman, USA) in accordance with manufacturer's instructions. The optical density was measured at 570 $\mathrm{nm}$. Nanoparticles which were previously calculated for magnetite concentration were diluted according to used antibody concentration. Evaluating of the effect of ranibizumab to HUVEC proliferation was also desired with antibody conjugated nanoparticles. Therefore first of all ranibizumab doses which can inhibit proliferation were determined with MTT test in accordance with manufacturer's instructions. $1 \mu \mathrm{g} / 100 \mu \mathrm{L}, 2.5 \mu \mathrm{g} / 100$ $\mu \mathrm{L}, 5 \mu \mathrm{g} / 100 \mu \mathrm{L}, 7.5 \mu \mathrm{g} / 100 \mu \mathrm{L}$ and $10 \mu \mathrm{g} / 100 \mu \mathrm{L}$ of ranibizumab doses were used to evaluating of antiangiogenic properties.

\section{RESULTS AND DISCUSSION}

\section{Characterization of Gold Coated $\mathrm{Fe}_{3} \mathrm{O}_{4}$ Nanoparticles}

Magnetite nanoparticles prepared the coprecipitation method are black colored and, after the gold coating process, red-brown color. The change in color indicates that the particles were coated with gold Figure 1: A and C.

Pure gold nanoparticles may form during the coating process of magnetite nanoparticles. For this reason a separation step was performed with an external magnet and the gold nanoparticles were separated from gold coated $\mathrm{Fe}_{3} \mathrm{O}_{4}$ (Wagstaff et al., 2012). Particles the solution moved towards the magnet outside of the vial. The supernatant solution had reddish color because the gold nanoparticles formed during coating procedure. The movement of the particles indicated that gold coated nanoparticles still preserved magnetic properties as magnetite Figure 1.B and D. Gold coated $\mathrm{Fe}_{3} \mathrm{O}_{4}$ nanoparticles combine $\mathrm{Au}$ characteristics and magnetite nanoparticles. Thus, these nanoparticles display optical properties for imaging and therapy. Nanoparticles can also be remotely delivered by an external magnetic field of targeted tissue in the body. It was shown that prepared nanoparticles have these properties as stated in the literature (Majouga et al.,2014).

Prepared nanoparticles were entitled with codes. The code for gold coated $\mathrm{Fe}_{3} \mathrm{O}_{4}$ nanoparticles was $\mathrm{N}$ before antibody conjugation. The code for $30 \mu \mathrm{g}$ of antibody conjugated nanoparticles was $\mathrm{N} 1,45 \mu \mathrm{g}$ of antibody conjugated nanoparticles was $\mathrm{N} 2$ and $60 \mu \mathrm{g}$ of antibody conjugated nanoparticles was N3 TABLE I. 


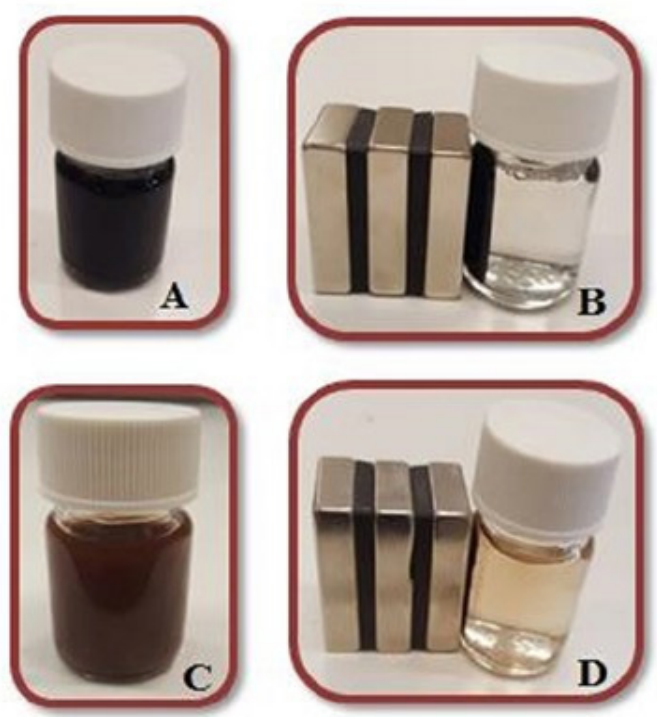

FIGURE 1 - A. $\mathrm{Fe}_{3} \mathrm{O}_{4}$ particles before magnetic separation, $\mathbf{B}$. $\mathrm{Fe}_{3} \mathrm{O}_{4}$ particles after magnetic separation, C. Gold coated $\mathrm{Fe}_{3} \mathrm{O}_{4}$ particles before magnetic separation, D. Gold coated $\mathrm{Fe}_{3} \mathrm{O}_{4}$ particles after magnetic separation and separated gold nanoparticles.
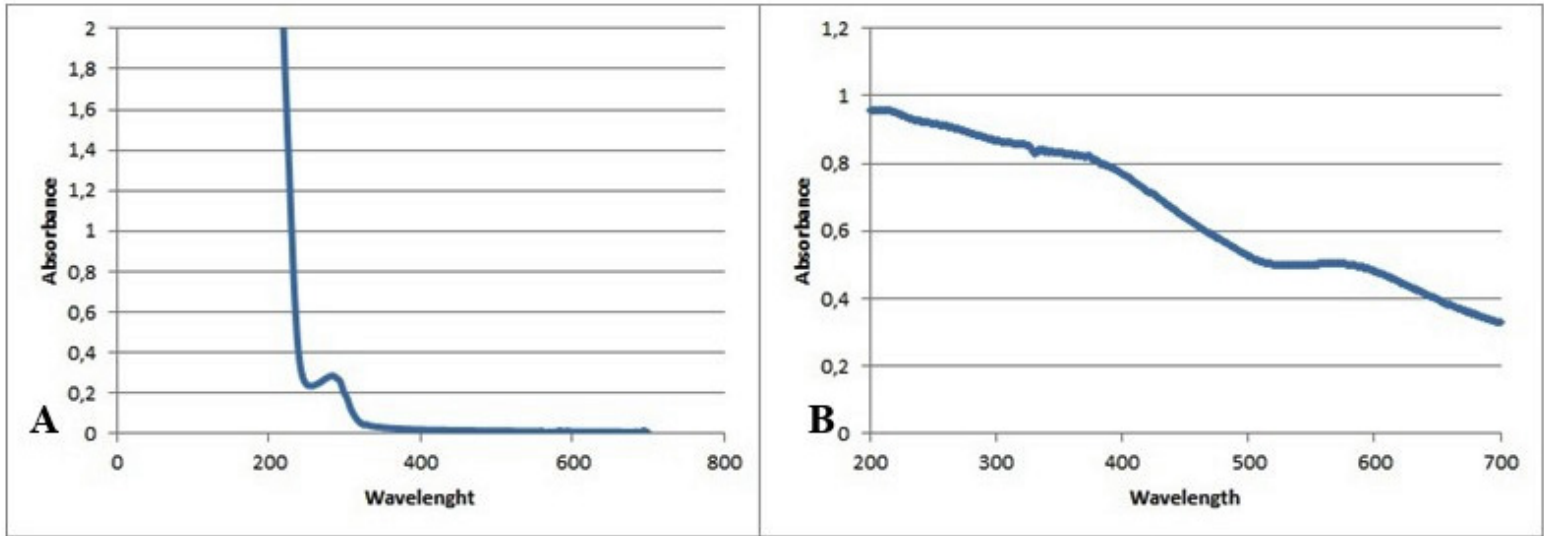

FIGURE 2 - Shows the UV spectrum of Ranibizumab and gold coated $\mathrm{Fe}_{3} \mathrm{O}_{4}$ nanoparticles.

Gold coated $\mathrm{Fe}_{3} \mathrm{O}_{4}$ nanoparticles were characterized by the Dynamic Light Scattering (DLS) technique. DLS is used for obtaining the size distribution and zeta potential of nanoparticles with and without antibodies. As shown in TABLE I, DLS analyses showed that gold coated $\mathrm{Fe}_{3} \mathrm{O}_{4}$ particles have average size of approximately 162 $\mathrm{nm}$. After antibody conjugation, size of nanoparticles increased depending on the amount of antibody. Size of the antibody conjugated nanoparticles changed between $232.9 \mathrm{~nm}$ and $472.8 \mathrm{~nm}$. The increase in nanoparticle size indicates to antibody binding.

Gold coated $\mathrm{Fe}_{3} \mathrm{O}_{4}$ nanoparticles were prepared with citrate so particles have negative surface charge
(Majouga et al., 2014). As shown in TABLE I, zeta potential of the gold coated nanoparticles were found to be -21.1. After conjugation, conjugated antibodies shielded a sum of negative charge and the zeta potential of N1 was measured to be -13.9. However, because of the negative charge of antibodies, the surface charge was measured as negative. The zeta potential of $\mathrm{N} 2$ and $\mathrm{N} 3$ were measured as -14.8 and -16.8 respectively. It was shown that the amount of conjugated antibody did not considerably affect the zeta potential. DLS analyses showed that surface charge changed between $-13.9 \mathrm{mV}$ and $-16.8 \mathrm{mV}$ (TABLE I). 


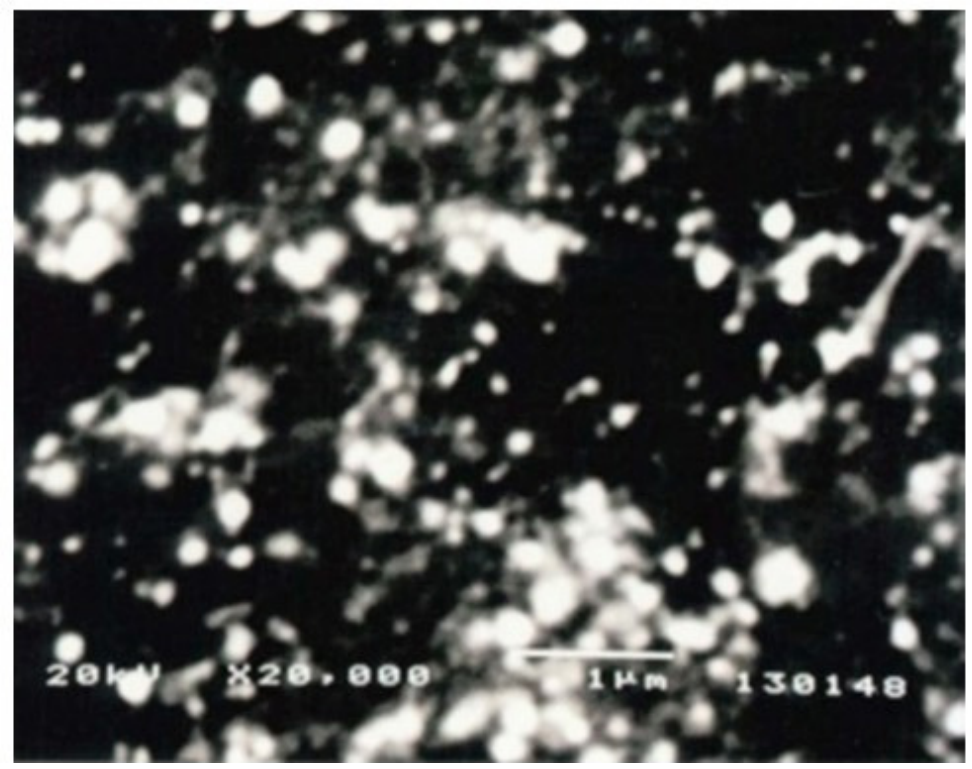

FIGURE 3 - SEM image of gold coated $\mathrm{Fe}_{3} \mathrm{O}_{4}$ particles $(\mathrm{N})$.

TABLE I - Code, size distribution, polidispersity index and zeta potential of gold coated $\mathrm{Fe}_{3} \mathrm{O}_{4}$ nanoparticles before and after antibody conjugation

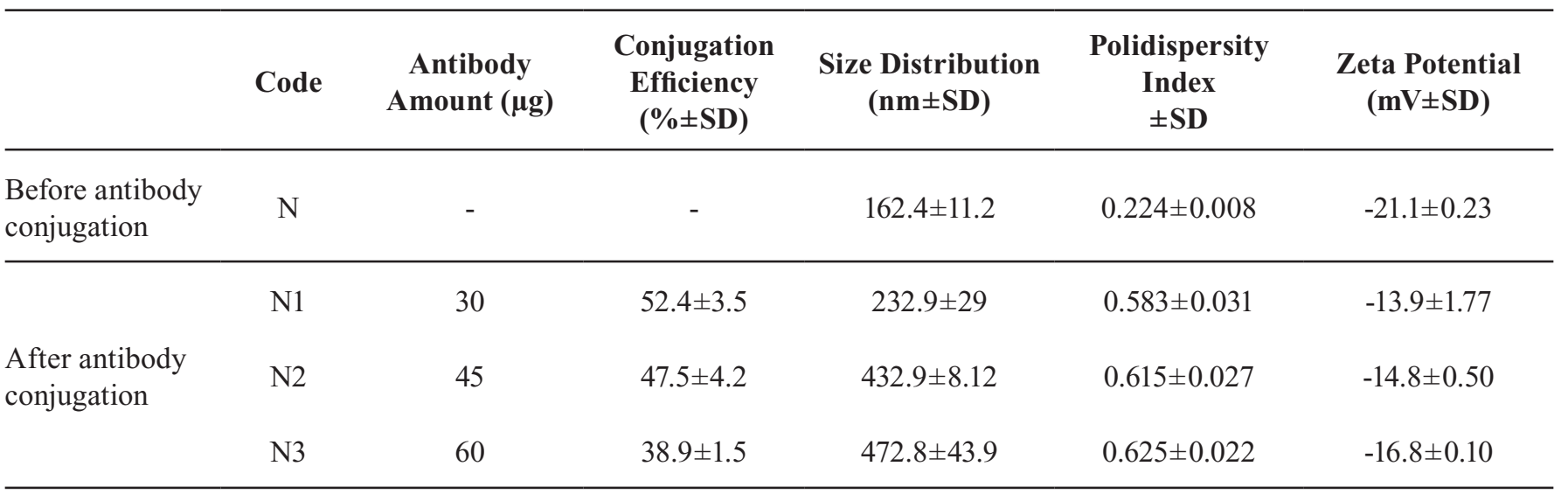

\section{X-ray Diffraction (XRD)}

The crystallographic properties of the gold coated $\mathrm{Fe}_{3} \mathrm{O}_{4}$ nanoparticles were recorded on an X-ray diffractometer (XRD) Figure 4. 


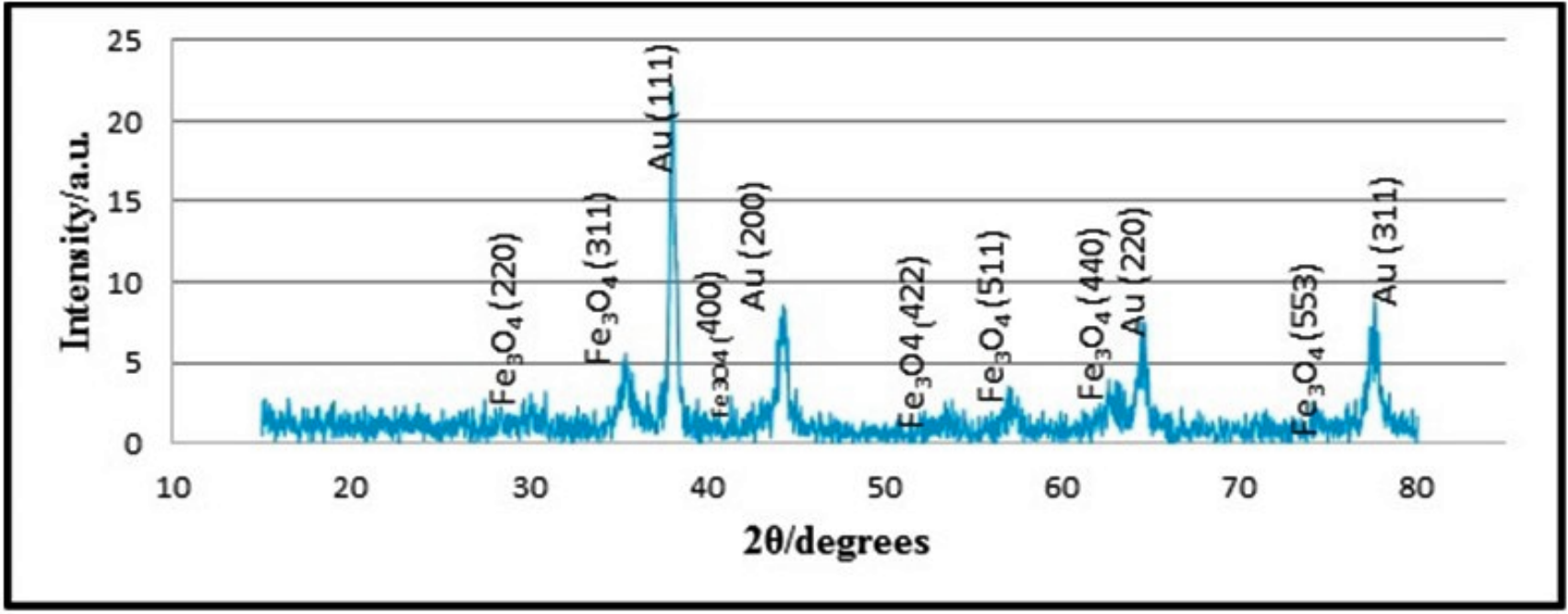

FIGURE 4 - Showed that, in the X-ray diffraction XRD pattern of gold coated $\mathrm{Fe}_{3} \mathrm{O}_{4}$ nanoparticles the main characteristic peaks of $\mathrm{Fe}$ and $\mathrm{Au}$ are clearly visible. XRD pattern have diffraction peaks at $2 \theta=38.2^{\circ}, 44.4^{\circ}, 65.6^{\circ}$ and $77.5^{\circ}$ which can be indexed to (111), (200), (220) and (311) planes of Au in the cubic phase (Robinson et al., 2010). Also have $30.3^{\circ}, 35.5^{\circ}, 43.2^{\circ}$, $53.5^{\circ}, 57^{\circ}, 62.7^{\circ}$ and $74.5^{\circ}$ which correspond to the (220), (311), (400), (422), (511), (440) and (533) crystallographic planes of the inverse spinel magnetite crystal (Shrifian et al., 2015). XRD results confirm the formation of gold coating on the magnetite nanoparticles.

\section{Antibody Conjugation and In vitro Release Studies}

The antibody conjugation process was performed in $20 \mathrm{mM}$ HEPES buffer ( $\mathrm{pH}: 6.8$ ) with shaker at 100 rpm. Antibody conjugation on gold coated $\mathrm{Fe}_{3} \mathrm{O}_{4}$ nanoparticles is based on noncovalent binding of the antibodies at their isoelectric point (Sokolov et al., 2003; El-Sayed et al., 2006; El-Sayed et al., 2005). This point is very important in terms of stability of the conjugates. Although theoretical pI value of ranibizumab is $\sim 8.8$, it was demonstrated that ranibizumab has net negative charge at $7.4 \mathrm{pH}$ (Li et al., 2011). As a result, $6.8 \mathrm{pH}$ was chosen because gold coated $\mathrm{Fe}_{3} \mathrm{O}_{4}$ nanoparticles have a negative charge at $7.4 \mathrm{pH}$.

In order to evaluate nanoparticle interference on antibody measurements, UV spectrometry measurements were performed with nanoparticles before antibody conjugation between $200 \mathrm{~nm}$ and $700 \mathrm{~nm}$. Obtained spectrum was used as baseline for antibody conjugated nanoparticles measurements. The calibration curve $\left(\mathrm{R}^{2}\right.$ value of 0.995$)$ was also obtained by recording the absorbance values of the antibodies with initial concentrations of $100 \mu \mathrm{g} / \mathrm{mL}$, which were serially diluted to $5 \mu \mathrm{g} / \mathrm{mL}$ at $280 \mathrm{~nm}$. The concentrations of unknown samples were estimated based on the antibody standard curve and nanoparticle baseline.

In the conjugation studies; it was found that although the amount of antibody increases, the efficiency of conjugation decreases as the antibody conjugated on the particle surface increased, TABLE I. The antibody conjugation efficacy changed between $38.9 \%$ and $52.4 \%$ dependent on the amount of antibody.

Ranibizumab molecules have net negative charge at pH 7.4 and electrostatic repulsion between ranibizumab and gold coated $\mathrm{Fe}_{3} \mathrm{O}_{4}$ particles will favor desorption. Hence, while conjugation studies were performed at 6.8 $\mathrm{pH}$, release studies were performed at $7.4 \mathrm{pH}$. In the in vitro release studies; it was found that although almost $60 \%$ of antibody is released within the first 30 minutes, $100 \%$ of antibody is released within 48 hours FIGURE 5. Release data is shown in TABLE II.

Preliminary studies showed that the antibody remained stable for 48 hours. According to the information in the literature, it has been shown that the stability of Ranibizumab was maintained for a long time in the stability studies performed at different $\mathrm{pH}$ values (Veurink et al., 2011). 


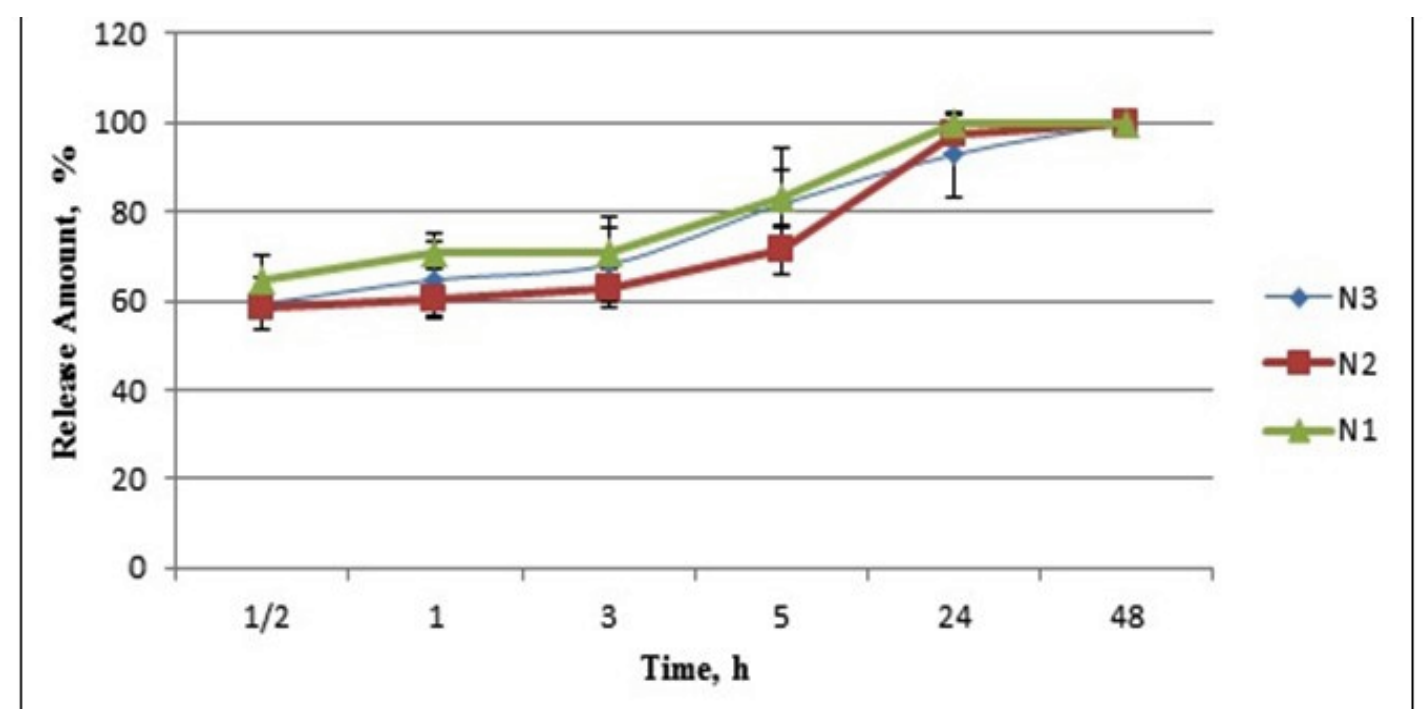

FIGURE 5 - showed that, in the X-ray diffraction (XRD) pattern of gold coated $\mathrm{Fe}_{3} \mathrm{O}_{4}$ particles the main characteristic peaks of $\mathrm{Fe}$ and $\mathrm{Au}$ are clearly visible. XRD pattern has diffraction peaks at $2 \theta=38.2^{\circ}, 44.4^{\circ}, 65.6^{\circ}$ and $77.5^{\circ}$, which can be indexed to (111), (200), (220) and (311) planes of Au in the cubic phase (Robinson et al., 2010). It also has $30.3^{\circ}, 35.5^{\circ}, 43.2^{\circ}, 53.5^{\circ}, 57^{\circ}$, $62.7^{\circ}$ and $74.5^{\circ}$ which correspond to the (220), (311), (400), (422), (511), (440) and (533) crystallographic planes of the inverse spinel magnetite crystal (Shrifian et al., 2015). XRD results confirm the formation of gold coating on magnetite nanoparticles.

TABLE II - Release data of antibody conjugated nanoparticles

\begin{tabular}{lcccccc}
\hline Code & $\begin{array}{c}\mathbf{3 0} \mathbf{m i n} \\
(\mathbf{\%} \pm \mathbf{S D})\end{array}$ & $\begin{array}{c}\mathbf{1} \mathbf{h} \\
(\mathbf{\%} \pm \mathbf{S D})\end{array}$ & $\begin{array}{c}\mathbf{3} \mathbf{h} \\
\mathbf{( \%} \pm \mathbf{S D})\end{array}$ & $\begin{array}{c}\mathbf{5} \mathbf{h} \\
(\mathbf{\%} \pm \mathbf{S D})\end{array}$ & $\begin{array}{c}\mathbf{2 4} \mathbf{h} \\
\mathbf{( \%} \pm \mathbf{S D})\end{array}$ & $\begin{array}{c}\mathbf{4 8} \mathbf{h} \\
(\mathbf{\%} \pm \mathbf{S D})\end{array}$ \\
\hline $\mathrm{N} 1$ & $64.5 \pm 5.4$ & $71.1 \pm 4.1$ & $70.6 \pm 8.3$ & $83.3 \pm 6.2$ & $98 \pm 1$ & 100 \\
$\mathrm{~N} 2$ & $58.5 \pm 2.1$ & $60.0 \pm 3.5$ & $62.5 \pm 4.3$ & $71.1 \pm 5.0$ & $97.5 \pm 4.2$ & 100 \\
$\mathrm{~N} 3$ & $59.3 \pm 5.6$ & $64.7 \pm 8.5$ & $68.0 \pm 8.5$ & $81.6 \pm 12.3$ & $92.8 \pm 9.7$ & 100 \\
\hline
\end{tabular}

\section{Thermogravimetric Analysis (TGA)}

The amount of ranibizumab on the surface of nanoparticles was determined by Thermogravimetric Analysis (TGA) in air atmosphere. The amount of ranibizumab on the surface of nanoparticles once and then dried in a vacuum oven at $60^{\circ} \mathrm{C}$ at $20 \mathrm{mbar}$. For TGA scan, temperature is increased from $25{ }^{\circ} \mathrm{C}$ to $600{ }^{\circ} \mathrm{C}$. Thermogravimetric analysis is employed to determine the weight of antibodies with respect to total weight of the sample, indicating the amount of antibodies present on the nanoparticle surface (Mukherjee et al., 2007). While mass loss of organic molecules such as water, citrate or antibody occurred below $600{ }^{\circ} \mathrm{C}$, mass loss of inorganic molecules such as gold or iron oxide were found to be above $800{ }^{\circ} \mathrm{C}$ (Villa et al.,2016; Van der Walt et al., 2010). In this study, only the mass loss of organic molecules was investigated therefor the temperature was increased to $600{ }^{\circ} \mathrm{C}$. This instrument measures the weight loss as a function of rising temperature as seen FIGURE 6.

As seen in FIGURE 6, A is mass loss of gold coated magnetite nanoparticles and is shown as $\left(\mathrm{W}_{\text {citrate }}+\mathrm{W}_{\mathrm{NP}}\right)-\mathrm{W}_{\text {citrate }}$, while $\mathrm{B}$ is mass loss of antibody conjugated gold coated magnetite nanoparticles and is shown as $\left(\mathrm{W}_{\text {citrate }}+\mathrm{W}_{\mathrm{NP}}+\mathrm{W}_{\mathrm{AB}}\right)-\left(\mathrm{W}_{\text {citrate }}+\mathrm{W}_{\mathrm{AB}}\right)$. In this equations, $W_{\text {citrate }}$ is mass of citrate on nanoparticle surface, $\mathrm{W}_{\mathrm{NP}}$ is the mass of nanoparticle, $\mathrm{W}_{\mathrm{AB}}$ is the mass of conjugated antibody on the nanoparticle surface. Before antibody conjugation, analyzed sample 
includes nanoparticles as inorganic molecules and citrate on nanoparticle surface as organic molecule. Due to the presence of citrate, a $14.6 \%$ weight loss was calculated after analysis. After antibody conjugation the analyzed sample includes nanoparticles as inorganic molecules and citrate and antibodies on nanoparticle surface as organic molecules. Due to the presence of citrate and antibody, 30.18\% weight loss was calculated after analysis. The difference between these two measurements reveals the amount of antibody that is associated with the nanoparticles. The difference of weight loss indicates the presence of antibody (Mukherjee et al., 2007). As a result, 15.58\% of the antibody conjugated nanoparticle sample was antibody and it was shown that antibody conjugation on nanoparticles was achieved with physical adsorption method successfully.

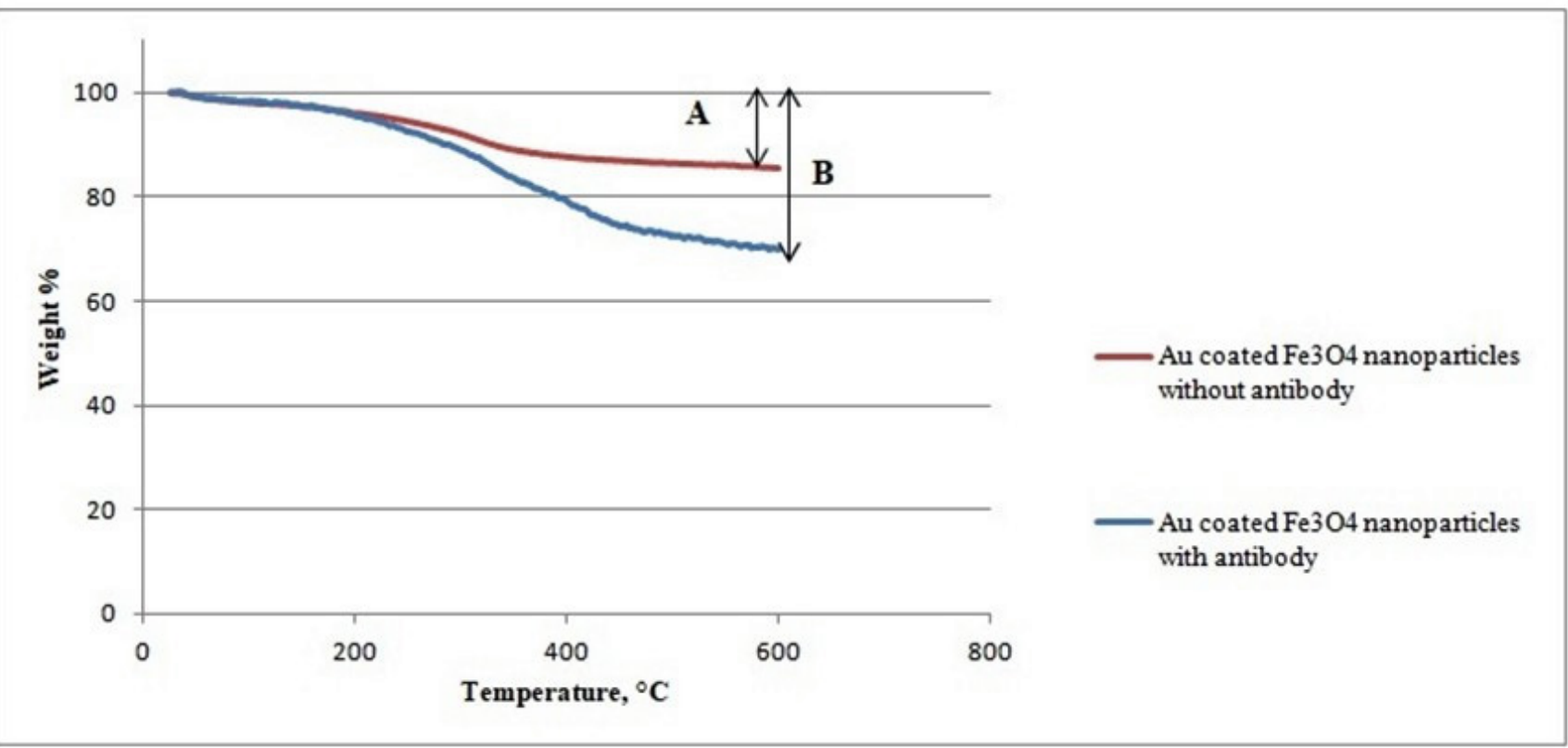

FIGURE 6 - Thermogravimetric analysis of gold coated $\mathrm{Fe}_{3} \mathrm{O}_{4}$ nanoparticles with and without antibody. A is mass loss of gold coated magnetite nanoparticles and is shown as $\left(\mathrm{W}_{\text {citrate }}+\mathrm{W}_{\mathrm{NP}}\right)-\mathrm{W}_{\text {citrate }}$, B is mass loss of antibody conjugated gold coated magnetite nanoparticles and is shown as $\left(\mathrm{W}_{\text {citrate }}+\mathrm{W}_{\mathrm{NP}}+\mathrm{W}_{\mathrm{AB}}\right)-\left(\mathrm{W}_{\text {citrate }}+\mathrm{W}_{\mathrm{AB}}\right)$.

\section{Enzyme Linked Immunosorbent Assay (ELISA) Test}

After in vitro drug release studies, sample concentrations were quantified using a commercially available Ranibizumab ELISA kit (Alpha Diagnostic International, USA) in accordance with manufacturer's instructions. Biological functionality of the released antibodies also was evaluated. The results show that the antibody retains its biological activity after release from the nanoparticle.

ForELISA test, only N2-code of antibody conjugated nanoparticles were used. The analysis demonstrated that, similar release profiles were obtained with UV Spectroscopy and ELISA. The results showed that, while approximately $50 \%$ conjugation efficiency was calculated with UV Spectroscopy, while approximately $42.8 \%$ conjugation efficiency was calculated with ELISA test. The reason for this difference is that the ELISA test is a very sensitive method. The samples collected with the help of an external magnet may also contain nanoparticles in small quantities. As a result, the UV measurements may be affected. The conjugation efficiency calculated with UV Spectroscopy and ELISA were compared in TABLE III. 
TABLE III - Comparing of conjugation efficiency calculated with UV Spectroscopy and ELISA for N2-code of antibody conjugated nanoparticles

\begin{tabular}{lcc}
\hline Code & $\begin{array}{c}\text { Conjugation efficiency calculated } \\
\text { with UV Spectroscopy (\%) }\end{array}$ & $\begin{array}{c}\text { Conjugation efficiency calculated } \\
\text { with ELISA (\%) }\end{array}$ \\
\hline $\mathrm{N} 2-1$ & $47.45 \%$ & $41.57 \%$ \\
$\mathrm{~N} 2-2$ & $56.20 \%$ & $48.26 \%$ \\
$\mathrm{~N} 2-3$ & $49.04 \%$ & $40.00 \%$ \\
$\mathrm{~N} 2-4$ & $50.63 \%$ & $41.37 \%$ \\
Ave & $50.83 \%$ & $42.8 \%$ \\
\hline
\end{tabular}

\section{Cell Culture Experiments}

The cytotoxicity of gold coated $\mathrm{Fe}_{3} \mathrm{O}_{4}$ nanoparticles was determined using a commercially available MTT kit (Cayman, USA) in accordance with manufacturer's instructions. Also, evaluating the effect of ranibizumab to HUVEC proliferation was desired for antibody conjugated nanoparticles. All ranibizumab doses that can inhibit proliferation were determined with MTT test in accordance with manufacturer's instructions.

The antibody concentrations that can be obtained by this system were chosen as max concentration. $1 \mu \mathrm{g} / 100 \mu \mathrm{L}, 2.5 \mu \mathrm{g} / 100 \mu \mathrm{L}, 5 \mu \mathrm{g} / 100 \mu \mathrm{L}, 7.5 \mu \mathrm{g} / 100$ $\mu \mathrm{L}$ and $10 \mu \mathrm{g} / 100 \mu \mathrm{L}$ of Ranibizumab doses were used to evaluate anti-angiogenic properties. These doses were administered to HUVEC cell and after 24 hours MTT test was performed. As observed in FIGURE 7 , cell viability was not affected by ranibizumab at any concentration tested (Carneiro et al., 2009). The prepared concentrations were inadequate to prevent the proliferation of cells. It is necessary to use more nanoparticles to achieve higher concentrations with this drug system. This situation reduces the usability of the system, because low conjugation efficiency was obtained by the physical adsorption method. As a result, cell culture studies with antibody conjugated $\mathrm{Fe}_{3} \mathrm{O}_{4}$ nanoparticles were not performed.

In the study of Lowe et al. in which the effect of ranibizumab on HUVEC proliferation was measured, it was shown that concentrations of $1.29 \mathrm{nM}$ and

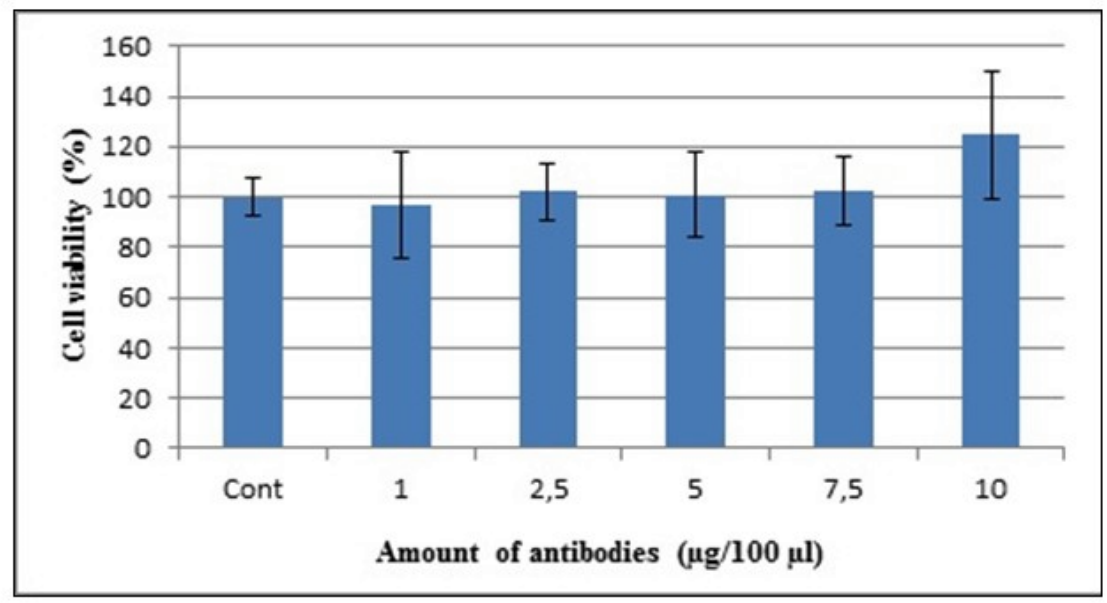

FIGURE 7 - MTT test for evaluation of anti-angiogenic properties of ranibizumab with prepared concentration. 
higher prevented proliferation (Lowe et al., 2007). In the study of Carneiro et al. it was demonstrated that ranibizumab concentrations of $0.06,0.125$ and $0.6 \mathrm{mg} /$ $\mathrm{mL}$, which were tested in HUVEC cells did not show toxicity. In addition, it is shown that ranibizumab prevents proliferation at a concentration of $0.6 \mathrm{mg} /$ $\mathrm{mL}$ (Carneiro et al., 2009). Although, the doses used in our study were found to be insufficient to prevent proliferation, ranibizumab is an FDA approved drug for AMD and its effect on proliferation has been proven.

The cytotoxicity studies were performed with the amounts of nanoparticles which could be provided with evaluating ranibizumab doses. These doses determined as $\mathrm{Fe}_{3} \mathrm{O}_{4}$ concentration calculated the Tiron test. $0.1 \mu \mathrm{g} /$ $\mathrm{mL}, 0.25 \mu \mathrm{g} / \mathrm{mL}, 0.5 \mu \mathrm{g} / \mathrm{mL}, 0.75 \mu \mathrm{g} / \mathrm{mL}$ and $1 \mu \mathrm{g} / \mathrm{mL}$ of concentrations were used for the MTT test. The results showed that the prepared nanoparticles are not toxic for HUVEC cells as indicated in the literature, Figure 8 (Soenen et al., 2011; Raju et al., 2011). However, the magnetite concentration and cell viability could not be correlated.

In the eye, the clearance mechanism of nanoparticles is unknown, but could involve uptake into the vascular system or passage through the hyaloid into the anterior chamber and egress out of the trabecular meshwork. After exiting the eye, the nanoparticles might be transported the lymphatic or systemic circulations and excreted in the liver and kidney. To evaluate ocular toxicity of magnetic nanoparticles, $50 \mathrm{~nm}$ and $4 \mu \mathrm{m}$ dextran coated magnetic nanoparticles were injected by intravitreally to Sprague-Dawley rats. After 5 months iron deposition was only detected after $4 \mu \mathrm{m}$ magnetic nanoparticles but not $50 \mathrm{~nm}$ magnetic nanoparticle injections. Of the $50 \mathrm{~nm}$ magnetic nanoparticles which were cleared from the vitreous in these experiments, $4 \mu \mathrm{m}$ particles were still detectable at 5 months. Intravitreal injections of magnetic nanoparticles also showed no signs of toxicity on retinal structure (Raju et al., 2011).

20 and $80 \mathrm{~nm}$ citrate stabilized gold nanoparticles are administered on ex vivo cultured post-natal mouse retina. Gold nanoparticles of both sizes were taken up by the retinal tissue and found to be distributed in all neuronal layers of the retina. Experimental studies show that gold nanoparticles after intravenous injection in mice pass cross the blood-retinal barrier and are detected in the CNS after systemic administration and induced no cytotoxicity in the retina (Söderstjerna et al., 2014; Kim et al., 2009).

Using uncoated MNPs (not studied here) in vivo can be harmful, as it could lead to aggregation, increased oxidation, and/or other instability in physiologic conditions. Adapting the surface of the particles can enhance biological compatibility and allow functionalization of the surfaces to deliver drugs or to bind receptors on target sites. Iron oxide nanoparticles or or gold nanoparticles are safe to be used for biomedical purposes. For gold nanoparticles, the high persistence of the core itself does not require any special coatings in this regard (Raju et al., 2011; Soenen et al., 2011).

The FDA has approved the use of superparamagnetic iron oxide nanoparticles as contrast agents in magnetic resonance imaging since 1996 (U.S. Food and Drug Administration), supporting the premise that nanoparticles prepared using iron oxide are not significantly harmful towards humans (Raju et al., 2011).

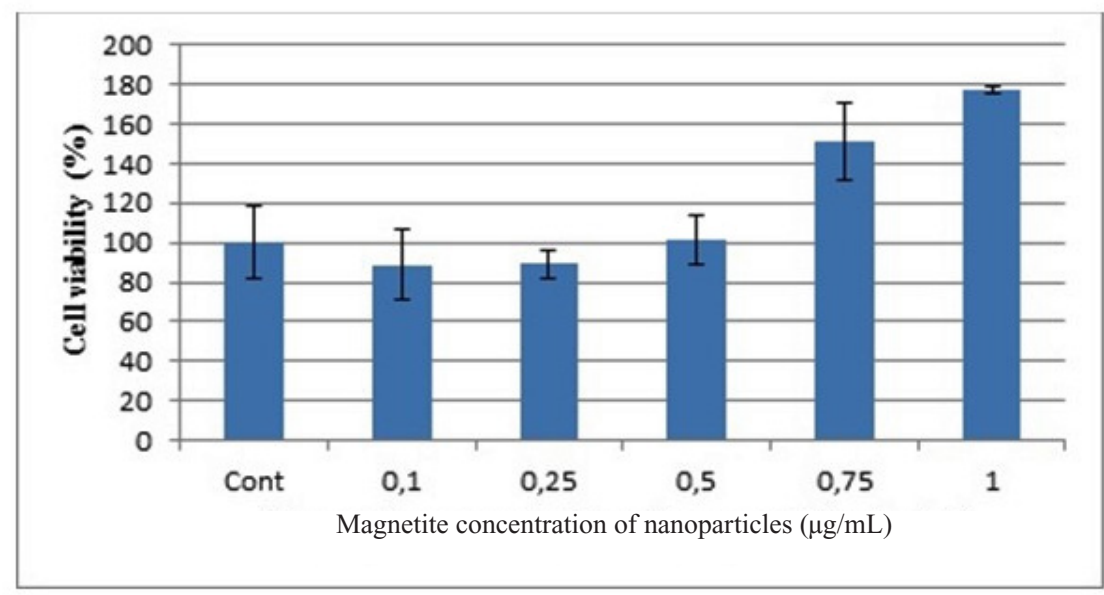

FIGURE 8 - MTT test for evaluation of cytotoxicity of gold coated $\mathrm{Fe}_{3} \mathrm{O}_{4}$ nanoparticles. 


\section{CONCLUSION}

The results obtained indicate that gold coated $\mathrm{Fe}_{3} \mathrm{O}_{4}$ nanoparticles could be synthesized and antibodies could can be conjugated on these nanoparticles. The nanoparticles were characterized by several techniques, which demonstrated a system containing gold coated $\mathrm{Fe}_{3} \mathrm{O}_{4}$ nanoparticles which antibody was conjugated. These nanoparticles could be controlled and moved with an external magnetic field allowing drug release to be potentially localized to a specific area. This technology can be used potentially in ocular diseases for intravenous administration of anti-VEGF agents. Thus adverse events and complications associated with intravitreal injection can be eliminated. The technology developed here can be used to design further nanoparticles systems which can examine the application of different antibodies or different conjugation techniques.

\section{ACKNOWLEDGEMENTS}

This study supported by the Marmara University Scientific Research Project Coordination Unit (BAPKO) (Project Number: SAG-C-YLP-110915-0423). We also give thanks to ATABAY Kimya San. Ve Tic. A.S. for the generous gift.

\section{REFERENCES}

Ahmed OS, Zekri A, Imam H, Khaled H, Abdel-Kader M. Synthesis of the newly developed core-shell au/ $\mathrm{Fe}_{3} \mathrm{O}_{4}$ magnato-plasmonic nanocomposite in cancer cells. Life Sci. J. 2014;11(10):182-187.

Akbarzadeh A, Samiei M, Davaran S. Magnetic nanoparticles: preparation, physical properties, and applications in biomedicine. Nanoscale Research Letters. 2012;7(1):144.

Avery, R. L., Pieramici, D. J., Rabena, M. D., Castellarin, A. A., Ma'an, A. N., Giust, M. J., Intravireal bevacizumab (Avastin) for neovascular age-related macular degeneration, Ophtalmology, 2006:113(3):363-372.

Baca M, Presta LG, O'Connor SJ, Wells JA. Antibody humanization using monovalent phage display. Journal of Biological Chemistry. 1997;272(16):10678-10684.

Bucak S, Rende D. Synthesis of Magnetite Nanoparticles, Colloid and Surface Chemistry: a laboratory guide for exploration of the nano world. CRC Press; 2013.
Bucak S, Yavuzturk B, Demir AD. Magnetic Nanoparticles: Synthesis, Surface Modifications and Application in Drug Delivery, Demir, A., editor. Recent Advances in Novel Drug Carrier Systems, InTech. 2012.

Carneiro Â, Falcão M, Pirraco A, Milheiro-Oliveira P, Falcão-Reis F, Soares R. Comparative effects of bevacizumab, ranibizumab and pegaptanib at intravitreal dose range on endothelial cells. Experimental Eye Research. 2009;88(3):522-527.

Chen Y, Wiesmann C, Fuh G, Li B, Christinger HW, Mckay P, De Vos AM, Lowman HB. Selection and analysis of an optimized anti-VEGF antibody: crystal structure of an affinity- matured Fab in complex with antigen. Journal of Molecular Biology. 1999;293(4):865-881.

El-Sayed IH, Huang X, El-Sayed MA. Surface plasmon resonance scattering and absorption of anti-EGFR antibody conjugated gold nanoparticles in cancer diagnostics: applications in oral cancer. Nano Letters. 2005;5(5):829-834.

El-Sayed IH, Huang X, El-Sayed MA. Selective laser photothermal therapy of epithelial carcinoma using anti-EGFR antibody conjugated gold nanoparticles. Cancer Letters. 2006;239(1):129-135.

Eter N, Krohne T U, Holz F G. New pharmacologic approaches to therapy for age-related macular degeneration. BioDrugs. 2006;20(3):167-179.

Ferrara N, Damico L, Shams N, Lowman H, Kim R. Development of ranibizumab, an anti- vascular endothelial growth factor antigen binding fragment, as therapy for neovascular age- related macular degeneration. Retina. 2006;26(8):859-870.

Frimpong R A, Hilt J Z. Magnetic nanoparticles in biomedicine: synthesis, functionalization and applications. Nanomedicine. 2010;5(9):1401-1414.

Gupta AK, Gupta M. Synthesis and surface engineering of iron oxide nanoparticles for biomedical applications. Biomaterials. 2005;26(18):3995-4021.

Issa B, Obaidat I M, Albiss BA, Haik Y. Magnetic nanoparticles: surface effects and properties related to biomedicine applications. Int J Mol Sci. 2013;14(11):2126621305.

Jager RD, Mieler WF, Miller J W. Age-related macular degeneration. New England Journal of Medicine. 2008;358(24):2606-2617.

Jazayeri MH, Amani H, Pourfatollah AA, Pazoki-Toroudi H, Sedighimoghaddam B. Various methods of gold nanoparticles 
(GNPs) conjugation to antibodies. Sensing and Bio-sensing Research. 2016;9:17-22.

Kim JH, Kim JH, Kim KW, Kim MH, Yu YS. Intravenously administered gold nanoparticles pass through the bloodretinal barrier depending on the particle size, and induce no retinal toxicity. Nanotechnology. 2009: 20(50), p.505101.

Kourlas H, Schiller DS. Pegaptanib sodium for the treatment of neovascular age-related macular degeneration: a review. Clinical Therapeutics. 2006;28(1):36-44.

Li SK, Liddell MR, Wen H. Effective electrophoretic mobilities and charges of anti-VEGF proteins determined by capillary zone electrophoresis. Journal of Pharmaceutical and Biomedical Analysis. 2011;55(3):603-607.

Lim LS, Mitchell P, Seddon JM, Holz FG, Wong TY. Age-related macular degeneration. The Lancet. 2012;379(9827):1728-1738.

Lowe J, Araujo J, Yang J, Reich M, Oldendorp A, Shiu V, et al. Ranibizumab inhibits multiple forms of biologically active vascular endothelial growth factor in vitro and in vivo. Experimental Eye Research. 2007;85(4):425-430.

Majouga, A., Sokolsky-Papkov, M., Kuznetsov, A., Lebedev, D., Efremova, M., Beloglazkina, E., et al. Enzymefunctionalized gold-coated magnetite nanoparticles as novel hybrid nanomaterials: synthesis, purification and control of enzyme function by low-frequency magnetic field. Colloids and Surfaces B: Biointerfaces, 2015, 125: 104-109.

Mukherjee P, Bhattacharya R, Bone N, Lee YK, Patra CR, Wang S, et al. Potential therapeutic application of gold nanoparticles in B-chronic lymphocytic leukemia (BCLL): enhancing apoptosis. Journal of Nanobiotechnology. 2007;5(1):4.

Nagarajan R, Hatton T. A. Nanoparticles: synthesis, stabilization, passivation, and functionalization. ACS Publications. 2008.

Orive G, Hernández RM, Gascón AR, Domínguez-Gil A, Pedraz JL. Drug delivery in biotechnology: present and future. Current Opinion in Biotechnology. 2003;14(6):659-664.

Penn, J. S., Madan, A., Caldwell, R. B., Bartoli, M., Caldwell, R. W., \& Hartnett, M. E. Vascular endothelial growth factor in eye disease. Prog Retin Eye Res. 2008;27(4):331-371.

Raju HB, Hu Y, Vedula A, Dubovy SR, Goldberg JL. Evaluation of magnetic micro-and nanoparticle toxicity to ocular tissues. PloS One. 2011;6(5):17452.
Robinson I, Tung LD, Maenosono S, Wälti C, Thanh NT. Synthesis of core-shell gold coated magnetic nanoparticles and their interaction with thiolated DNA. Nanoscale. 2010;2(12):2624-2630.

Schmidt-Erfurth U, Hasan T. Mechanisms of action of photodynamic therapy with verteporfin for the treatment of age-related macular degeneration. Survey of Ophthalmology. 2000;45(3):195-214.

Schweizer D, Serno T, Goepferich A. Controlled release of therapeutic antibody formats. Eur J Pharm Biopharm. 2014;88(2):291-309.

Shrifian-Esfahni A, Salehi MT, Nasr-Esfahni M, Ekramian E. Chitosan-modified superparamgnetic iron oxide nanoparticles: design, fabrication, characterization and antibacterial activity. Chemik. 2015;69(1):19-32.

Singh R, Lillard JW Jr. Nanoparticle-based targeted drug delivery. Exp Mol Pathol. 2009;86(3):215-223.

Soenen SJ, Rivera-Gil P, Montenegro JM, Parak WJ, De Smedt SC, Braeckmans K. Cellular toxicity of inorganic nanoparticles: common aspects and guidelines for improved nanotoxicity evaluation. Nano today. 2011;6(5):446-465.

Sokolov K, Follen M, Aaron J, Pavlova I, Malpica A, Lotan R, Richards-Kortum R. Real- time vital optical imaging of precancer using anti-epidermal growth factor receptor antibodies conjugated to gold nanoparticles. Cancer Research. 2003;63(9):1999-2004.

Söderstjerna E, Bauer P, Cedervall T, Abdshill H, Johansson F, Johansson UE. Silver and gold nanoparticles exposure to in vitro cultured retina-studies on nanoparticle internalization, apoptosis, oxidative stress, glial-and microglial activity. PLoS One. 2014:9(8), p.e105359.

Spitzer MS, Ziemssen F, Bartz-Schmidt KU, Gelisken F, Szurman P. Treatment of age-related macular degeneration: focus on ranibizumab. Clinical Ophthalmology. (Auckland, NZ), 2008;2(1):1-14.

Van Der Walt H, Chown L, Harris R, Sosibo N, Tshikhudo R. $\mathrm{Fe}_{3} \mathrm{O}_{4}$ and $\mathrm{Fe}_{3} \mathrm{O}_{4} @ \mathrm{Au}$ nanoparticles: synthesis and functionalisation for biomolecular attachment. World Acedemy Sci Eng Technol. 2010:4(8):560-564.

Van Leeuwe NR, Klaver CC, Vingerling JR, Hofman A, De Jong PT. Epidemiology of age- related maculopathy: a review. European Journal of Epidemiology. 2003;18(9):845-854.

Veurink M, Stella C, Tabatabay C, Pournaras CJ, Gurny R. Association of ranibizumab (Lucentis ${ }^{\circledR}$ ) or bevacizumab

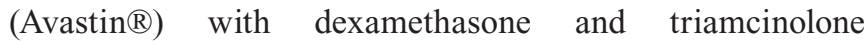


Preparation and In Vitro Characterization of Monoclonal Antibody Ranibizumab Conjugated Magnetic Nanoparticles for Ocular Drug Delivery

acetonide: an in vitro stability assessment. European Journal of Pharmaceutics and Biopharmaceutics. 2011;78(2):271-277.

Villa S, Riani P, Locardi F, Canepa F. Functionalization of $\mathrm{Fe}_{3} \mathrm{O}_{4}$ NPs by silanization: use of amine (APTES) and thiol (MPTMS) silanes and their physical characterization. Materials. 2016:9(10), p.826.

Volz C, Pauly D. Antibody therapies and their challenges in the treatment of age-related macular degeneration. Eur J Pharm Biopharm. 2015:95(Pt B):158-172.

Wagstaff AJ, Brown SD, Holden MR, Craig GE, Plumb JA, Brown RE, et al. Cisplatin drug delivery using gold-coated iron oxide nanoparticles for enhanced tumour targeting with external magnetic fields. Inorganica Chimica Acta. 2012;393:328-333.
Wang EC, Wang AZ. Nanoparticles and their applications in cell and molecular biology. Integrative Biology. 2014;6(1):9-26.

Witting M, Obst K, Friess W, Hedtrich S. Recent advances in topical delivery of proteins and peptides mediated by soft matter nanocarriers. Biotechnol Adv. 2015;33(6 Pt 3):1355-1369.

Xing Y. Jin, Y. Y., Si, J. C., Peng, M. L., Wang, X. F., Chen, C., et al. Controllable synthesis and characterization of $\mathrm{Fe}_{3} \mathrm{O}_{4} /$ $\mathrm{Au}$ composite nanoparticles. Journal of Magnetism and Magnetic Materials, 2015;380:150-156.

U.S. Food and Drug Administration (cited 2018 July 5). Available from: https://www.accessdata.fda.gov/scripts/cder/ daf/index.cfm?event $=$ overview.process \& applno $=020416$.

Received for publication on $26^{\text {th }}$ August 2018 Accepted for publication on $01^{\text {st }}$ April 2019 